\title{
Acute Generalized Chorea as Presenting Manifestation of Uremic Encephalopathy
}

Sir,

Renal dysfunction results in a clinical metabolic condition known as uremia. It causes altered mental status due to involvement of cerebral cortex termed as uremic encephalopathy. Acute hyperkinetic or hypokinetic extrapyramidal disorder in patients with uremia is a very rare syndrome. It was first described by Wang et al. due to bilateral basal ganglia lesions in uremia. ${ }^{[1]}$ Hereby, we report an elderly patient with diabetic nephropathy who presented with acute-onset generalized chorea. Brain magnetic resonance imaging (MRI) showed bilateral basal ganglia lesions. Choreiform movements got ameliorated with hemodialysis.

\section{CASE Report}

A 72-year-old male was brought to the emergency department with a history of disabling abnormal involuntary movements involving face and all limbs of 1-day duration. The movements were random, arrhythmic, continuous, nonstereotyped, partially suppressible that increased on activity. He had speech difficulty due to facial involuntary movements. There was no history of fever, altered mental status, seizures, myoclonus, diarrhea, or vomiting. He was diabetic and hypertensive of 7 years duration. He was diagnosed to have diabetic nephropathy for
1 year on medical management. On examination, his tongue was dry, pulse rate of $102 / \mathrm{min}$, blood pressure of $146 / 86 \mathrm{mmHg}$, and respiratory rate of 20 breaths/min. Neurologically, he was conscious and responding to verbal commands with mild slurred speech. Fundus examination was normal. There was generalized choreiform movement involving face and all limbs. Asterixis could not be made out due to choreiform movements of limbs. Tone in limbs was decreased with sluggish reflexes. Plantar response was withdrawal. There was no neck rigidity. Complete hemogram showed raised total leukocyte counts $(16,000$ cells per cumm), normal platelet count, and hemoglobin. Serum electrolytes, random blood glucose, serum ammonia, and liver and thyroid function test were normal. Blood urea nitrogen was $76.4 \mathrm{mg} / \mathrm{dl}$, creatinine of $6.2 \mathrm{mg} / \mathrm{dl}$, and glycosylated hemoglobin of $8.2 \%$. Blood gas analysis showed $\mathrm{pH}$ : 7.314, bicarbonate: $17.6 \mathrm{mmol} / \mathrm{L}$, and lactate: $2.1 \mathrm{mmol} / \mathrm{L}$. Brain MRI showed hypointense on T1 and hyperintense lesions on $\mathrm{T} 2$ and fluid-attenuated inversion recovery sequences in bilateral basal ganglia. Diffusion-weighted imaging showed no restriction in bilateral putamen [Figure 1]. Electroencephalogram showed mild slowing of background rhythm. He was started on sodium valproate (1 g/day) but had no improvement. He
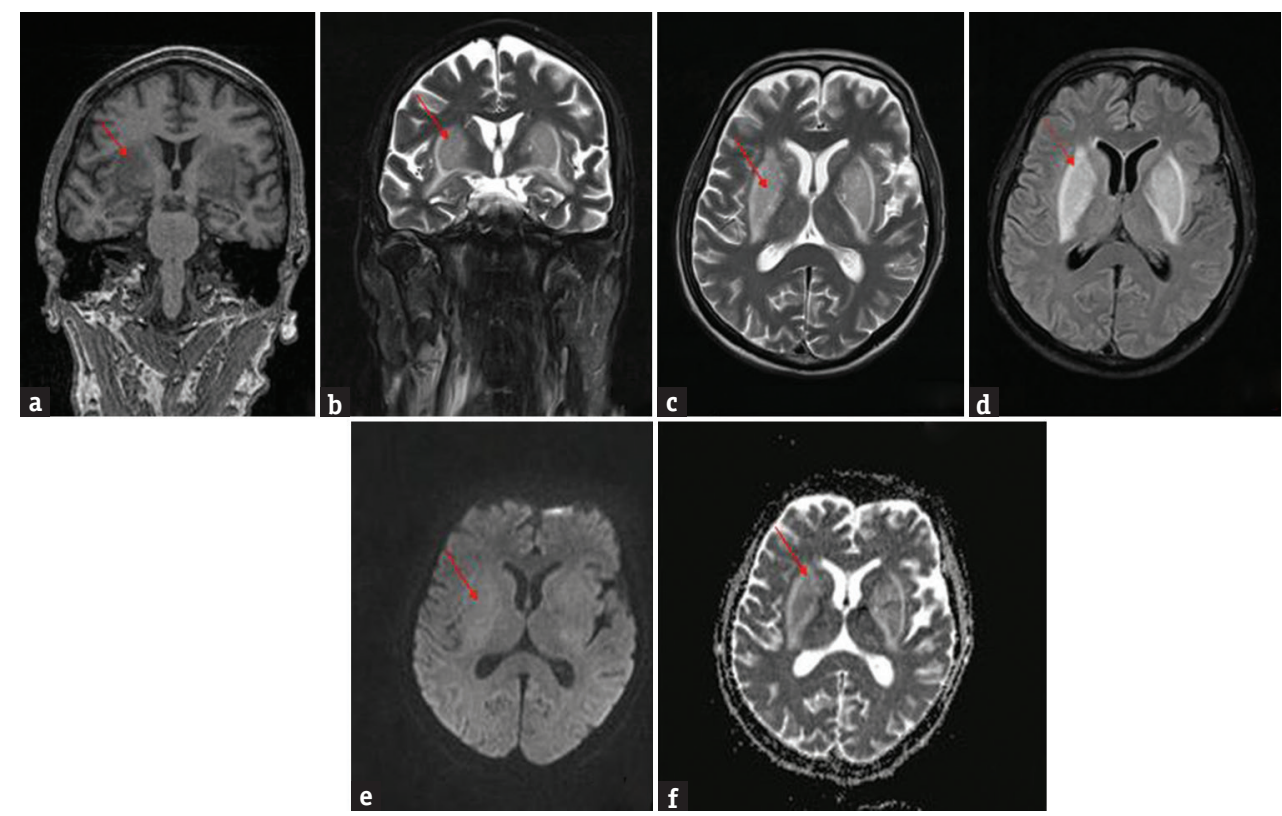

Figure 1: Brain magnetic resonance imaging T1 coronal view (a) showed hypointense lesions (red arrow); T2 coronal (b), and axial (c) fluid-attenuated inversion recovery (d) showed hyperintense lesions in bilateral putamen (red arrow); diffusion-weighted (e) and apparent diffusion coefficient (f) showed no restriction (red arrow) 
underwent hemodialysis with correction of metabolic acidosis. Choreiform movements gradually improved with concomitant decrease in creatinine level.

\section{Discussion}

Uremic encephalopathy is an organic brain syndrome involving the cerebral cortex that is characterized by altered mental state ranging from mild confusion to comatose state, tremor, asterixis, multifocal myoclonus, and seizures. ${ }^{[2]}$ The involvement of basal ganglia is rare. Wang et al. reported a unique clinical condition in diabetic uremic patients characterized by acute movement disorder due to bilateral basal ganglia lesions. This was most commonly reported in Asian patients. ${ }^{[3]}$ The movement disorder can be either acute parkinsonism with patients presenting with rigidity, bradykinesia, and postural instability or chorea as in our case. There are two cases of generalized chorea due to uremia reported in Indian patients so far. ${ }^{[4,5]}$

There are various explanations reported for the involvement of basal ganglia. Wang et al. performed F-18 fluorodeoxyglucose positron emission tomography on two diabetic uremic patients with bilateral basal ganglia lesions and demonstrated glucose hypometabolism in putamen, frontal, and occipital cortices. This may be due to compromised cellular function in basal ganglia due to diabetic microangiopathy or failure of utilization of energy compounded by the negative effects of uremic toxins and acid-base abnormalities on the basal ganglia cells. ${ }^{[6]}$ Basal ganglia lesions are due to cytotoxic edema surrounded by vasogenic edema (due to focal hyperemia secondary to abnormal dilatation of small vessels). ${ }^{[7]}$ Other explanations include hypoglycemia which may act as one of the trigger factors causing this syndrome as reported by Jurynczyk et al..$^{[8]}$ Tajima et al. suggested that the basal ganglia lesions may be due to demyelination. ${ }^{[9]}$ There is difference in the resolution of clinical and radiological abnormalities. The resolution of clinical abnormalities may be complete in one-fifth of the cases, partial in half of the cases, and no resolution in $30 \%$ of the cases. However, resolution of the radiological abnormalities is observed in almost $90 \%$ of the cases. ${ }^{[4]}$ Our patient had complete clinical recovery within 1 week of initiation of hemodialysis.

Other causes of bilateral basal ganglia lesions include hypoxia, hyperammonemia, hypoglycemia, hyperglycemia, osmotic demyelination syndrome, deep vein thrombosis, toxins such as carbon monoxide poisoning, viral encephalitis such as Japanese encephalitis, prionopathies such as Creutzfeldt-Jakob disease, and degenerative disease such as Wilson's disease.

\section{Conclusion}

Bilateral basal ganglia lesions in uremia are mainly due to the effects of metabolic abnormalities and uremic toxins on the compromised basal ganglionic cellular function causing cytotoxic and vasogenic edema. These abnormalities are potentially reversible if recognized promptly. This is the third reported Indian case of generalized chorea in uremia with bilateral basal ganglia lesions. The knowledge of this entity is necessary for the treating neurologists, nephrologists, and intensivist.

\section{Financial support and sponsorship}

Nil.

\section{Conflicts of interest}

There are no conflicts of interest.

Rohan R. Mahale, Kiran Buddaraju, M. S. Gireesh ${ }^{l}$, Purushottam Acharya, Rangasetty Srinivasa Departments of Neurology and ${ }^{1}$ Nephrology, MS Ramaiah Medical College and Hospital, Bengaluru - 560 054, Karnataka, India

\begin{abstract}
Address for correspondence: Dr. Rohan R. Mahale, Department of Neurology, M. S. Ramaiah Medical College and Hospital, Bengaluru - 560 054, Karnataka, India. E-mail: rohanmahale83@gmail.com
\end{abstract}

\section{REFERENCES}

1. Wang HC, Brown P, Lees AJ. Acute movement disorders with bilateral basal ganglia lesions in uremia. Mov Disord 1998;13:952-7.

2. Brouns R, De Deyn PP. Neurological complications in renal failure: A review. Clin Neurol Neurosurg 2004;107:1-16.

3. Wang HC, Cheng SJ. The syndrome of acute bilateral basal ganglia lesions in diabetic uremic patients. $J$ Neurol 2003;250:948-55.

4. Wali GM, Khanpet MS, Mali RV. Acute movement disorder with bilateral basal ganglia lesions in diabetic uremia. Ann Indian Acad Neurol 2011;14:211-3.

5. Mahajan PS, El Esnawi MA, Hussein SA, Al Maslamani NJ. Rare case of reversible acute symmetrical lesions of the bilateral Basal Ganglia associated with diabetic nephropathy and chronic renal failure. J Clin Imaging Sci 2014;4:29.

6. Wang HC, Hsu JL, Shen YY. Acute bilateral basal ganglia lesions in patients with diabetic uremia: An FDG-PET study. Clin Nucl Med 2004;29:475-8.

7. Lee EJ, Park JH, Ihn Yk, Kim YJ, Lee SK, Park CS. Acute bilateral basal ganglia lesions in diabetic uraemia: Diffusion-weighted MRI. Neuroradiology 2007;49:1009-13.

8. Jurynczyk M, Rozniecki J, Zaleski K, Selmaj K. Hypoglycemia as a trigger for the syndrome of acute bilateral basal ganglia lesions in uremia. J Neurol Sci 2010;297:74-5. 
9. Tajima Y, Mito Y, Yanai M, Fukazawa Y. Unusual basal ganglia lesions in a diabetic uraemic patient proven to be demyelination: First pathological observation. BMJ Case Rep 2012;2012. pii: Bcr2012006522.

This is an open access article distributed under the terms of the Creative Commons Attribution-NonCommercial-ShareAlike 3.0 License, which allows others to remix, tweak, and build upon the work non-commercially, as long as the author is credited and the new creations are licensed under the identical terms.

\begin{tabular}{|l|l|}
\hline \multicolumn{2}{|c|}{ Access this article online } \\
\hline Quick Response Code: & Website: \\
\hline & www.ruralneuropractice.com \\
& \\
& \\
\hline
\end{tabular}

How to cite this article: Mahale RR, Buddaraju K, Gireesh MS, Acharya P, Srinivasa R. Acute Generalized Chorea as Presenting Manifestation of Uremic Encephalopathy. J Neurosci Rural Pract 2017;8:S156-8.

(C) 2017 Journal of Neurosciences in Rural Practice | Published by Wolters Kluwer - Medknow 